\title{
Nível e Evolução da Desigualdade dos Gastos Familiares no Brasil: uma Análise para as Regiões Metropolitanas no Período 1996 a $2003^{\dagger}$
}

\author{
- Raul da Mota Silveira Neto * - Tatiane Almeida de Menezes *夫
}

\begin{abstract}
Resumo
A partir da utilização dos microdados da Pesquisa de Orçamento Familiar (POF) dos biênios 1995-96 e 2002-03, o trabalho fornece evidências a respeito dos níveis e da evolução da desigualdade da distribuição dos gastos familiares per capita e da desigualdade da distribuição do consumo familiar per capita no Brasil metropolitano e a respeito da importância dos diferentes tipos de gastos familiares nas dinâmicas observadas. Os resultados, obtidos a partir de indicadores tradicionais de desigualdade e de análises de Dominância de Lorenz, apontam para importantes movimentos em termos de diminuição da desigualdade em ambos os tipos de gastos. Medida a desigualdade pelo índice de Gini, observa-se que a redução deste índice é afetada de forma significativa pelas dinâmicas dos gastos com Habitação, Higiene e Cuidados Pessoais e Vestuário, favoráveis à diminuição da desigualdade, e pelas as dinâmicas dos gastos com Educação, Saúde e Alimentação, favoráveis à desigualdade. Diferenças regionais são apontadas a partir das regiões metropolitanas de Recife e São Paulo.
\end{abstract}

\section{Palavras-Chave}

desigualdade, gastos, consumo, índice de Gini

\begin{abstract}
By using micro data from the Pesquisa de Orçamento Familiar (POF) for years of 1995-96 and 2002-03, the paper presents evidence about the evolution of the inequality levels for per capita familiar spending and per capita familiar consumption distributions in Brazil metropolitan regions. The results, obtained by using traditional inequality indicators and Lorenz Dominance, show that the dynamics of inequality for these distributions present important movements favoring inequality reduction. Spending dynamic of Habitation, Hygiene and Personal Care and of Wearing favored total consumption inequality and the dynamic spending of Education, Health and Food favored total consumption inequality increasing. Regional differences are highlighted by considering the cases of Recife and São Paulo metropolitan regions.
\end{abstract}

\section{Keywords}

inequality, expenditure, consumption, Gini index

\section{JEL Classification}

O12, O15, 018

+ Os autores, únicos responsáveis por eventuais erros e imprecisões, agradecem aos pesquisadores Fernando Gaiger Silveira e a Bernardo Palhares Campolina Diniz, ambos do IPEA, pelo decisivo auxílio na montagem dos microdados da Pesquisa de Orçamento Familiar (POF), e a Rodolfo Hoffmann pelos comentários a uma versão preliminar.

* Programa de Pós-Graduação em Economia, Universidade Federal de Pernambuco (PIMES/UFPE) e CNPq. E-mail: rau.silveira@uol.com.br.

** Programa de Pós-Graduação em Economia, Universidade Federal de Pernambuco (PIMES/UFPE) e CNPq. E-mail: tatianedemenezes@terra.com.br.

Endereço para contato: Universidade Federal de Pernambuco - Centro de Ciências Sociais Aplicadas - Departamento de Economia - Av. dos Economistas, s/n - Cidade Universitária - Recife - PE. CEP: 50670-901.

(Recebido em maio de 2008. Aceito para publicação em maio de 2009). 


\section{Introdução}

Recentemente, um conjunto de trabalhos apontou para um importante movimento na distribuição da renda familiar per capita brasileira: ao menos desde a segunda metade dos anos de 1990, o nível de desigualdade tem se reduzido (BARROS et al. 2006; FERREIRA et al., 2006; HOFFMANN, 2006; SOARES, 2006b). Tal movimento merece destaque, já que, como se sabe, as condições de bem-estar e pobreza da população do País são fortemente vinculadas ao elevado nível de desigualdade na distribuição da renda.

Pouca evidência, contudo, foi até aqui apresentada a respeito da evolução da desigualdade da distribuição dos gastos ou consumo das famílias do País, variáveis mais diretamente vinculadas ao bem-estar da população. Na verdade, além deste maior vínculo com as condições de bem-estar, como bem já havia destacado Hoffmann (2000), a consideração da evolução da distribuição dos gastos ou consumo familiar per capita permite, em alguma medida, transplantar as dificuldades na mensuração da renda, já que parte desta é sabidamente omitida nas pesquisas domiciliares como, por exemplo, a Pesquisa Nacional por Amostra de Domicílios (PNAD). Adicionalmente, a possibilidade de decompor as mudanças dos níveis de desigualdade da distribuição do consumo entre as mudanças dos diferentes tipos de gastos (ex. alimentação, habitação, educação, etc.) permite uma compreensão mais precisa a respeito da natureza das mudanças na distribuição dos níveis de bem-estar da população no período recente.

A partir da utilização de microdados da Pesquisa de Orçamento Familiares (POF), o objetivo deste trabalho é fornecer um conjunto de evidências a respeito da evolução dos níveis da desigualdade do gasto familiar per capita e do consumo familiar per capita da população das regiões metropolitanas brasileiras entre os biênios de 1995-96 e 2002-03 que, diferenciando-se dos enfoques baseados em desigualdades apenas de renda, permita maior compreensão sobre a evolução dos desníveis de bem-estar desta população.

Nesta tarefa, o trabalho compara, em primeiro lugar, a evolução dos níveis de desigualdade da renda familiar per capita com a evolução dos níveis de desigualdades do gasto familiar per capita e do consumo familiar per capita. Em seguida, por meio de uma decomposição, investiga em que medida a constatada diminuição da desigualdade dos gastos totais é explicada pela diminuição dos níveis de desigualdade dos gastos em consumo e ou dos demais gastos. Adicionalmente, aplicando-se a mesma decomposição, são determinados os diferentes tipos de gastos em consumo responsáveis pela diminuição da desigualdade da distribuição do consumo total familiar per capita entre os biênios 1995-96 e 2002-03. Por fim, considerando-se 
especificamente as regiões metropolitanas do Recife e de São Paulo, as regiões metropolitanas mais populosas da região mais pobre (Nordeste) e da mais rica (Sudeste) do País, são apontadas importantes diferenças regionais tanto no ritmo de queda da desigualdade do consumo familiar per capita, como na natureza da diminuição de sua desigualdade.

Além desta introdução, o trabalho apresenta mais quatro seções. Na próxima, descreve os dados utilizados na pesquisa e apresenta evidências iniciais a respeito da evolução dos níveis de desigualdade da distribuição da renda, da despesa total e do consumo. Na seção três, são apresentadas a metodologia de decomposição utilizada e os principais resultados da pesquisa. Na seção quatro, são apresentadas e discutidas evidências específicas para as regiões metropolitanas do Recife e de São Paulo. As conclusões são apresentadas na quinta e última seção.

\section{Descrição dos Dados e Evidências Iniciais}

\subsection{Os Dados Utilizados}

Os principais resultados deste trabalho foram obtidos com a utilização dos microdados da Pesquisa de Orçamento Familiar do IBGE (POF). Esta pesquisa fornece a estrutura de gastos das famílias brasileiras, tendo sido realizada em três períodos: 1987-88 1995-96 e 2002-03. As POFs disponibilizam também informações de renda e socioeconômicas como idade, raça, grau de instrução e sexo do chefe do domicílio, número de pessoas da família, etc. Tal pesquisa tem por finalidade a construção da estrutura de ponderação do Índice de Preços ao Consumidor do IBGE. Desta forma, as duas primeiras POFs foram realizadas apenas nas regióes metropolitanas brasileiras: Belém, Fortaleza, Recife, Salvador, Belo Horizonte, Rio de Janeiro, São Paulo, Curitiba e Porto Alegre, mais a cidade de Goiânia e o Distrito Federal (para facilitar a exposição, a partir deste momento serão todas chamadas de cidades). Nestas cidades, foram acompanhadas 14.000 famílias em 1988 e 16.000 famílias em 1996. Em 2002, a POF passou a ter abrangência nacional, entrevistando 48.568 famílias em todos os Estados brasileiros. Outra importante diferença entre as duas primeiras POFs e a última é que, nas duas primeiras, foram geradas informações apenas monetárias, enquanto, na última, existem dados de consumo e renda monetária e não monetária.

Neste artigo, optou-se por empregar dados apenas das duas últimas POFs, uma escolha motivada por duas razões. Primeiro, o período entre 1988 e 1996 inclui parte dos anos de hiperinflação do final dos anos de 1980, o que torna as comparações 
de bem-estar por meio dos gastos mais imprecisas. Por sua vez, como mostraram recentemente Hoffmann (2006) e Soares (2006b), no período entre 1996 e 2003, há significativa redução da desigualdade de renda no País, um comportamento, porém, não encontrado para o Brasil metropolitano. Assim, o foco neste período permite investigar em que medida a dinâmica de desigualdade dos gastos em consumo reflete aquela da desigualdade da renda num período de inflação baixa, onde, simultaneamente, há expansão do crédito e mais fácil planejamento dos gastos.

Neste sentido, a compatibilização da POF 2002-03 com a POF 1995-96 requer a utilização apenas dos dados monetários para as 11 cidades anteriormente citadas. Além destes, outros ajustes foram necessários para permitir a comparação das duas pesquisas. Primeiro, o item aquisição de veículos próprios na POF de 2002-03 consta do grupo transporte, enquanto na POF de 1995-06 encontrava-se em aumento do ativo. Segundo Diniz et al. (2007), retiraram-se do grupo transporte da POF 2002-03 os gastos com veículos próprios. Além disto, diferentemente da POF de 1995-96, a POF 2002-03 imputa aos imóveis próprios os possíveis gastos com alugueis, o que implicou a necessidade de suprimir tais dados na análise. A tabulação dos dados com saúde também sofreu grandes alterações entre as duas POFs, o que, mais uma vez, para comparabilidade, levou à adoção das orientações sugeridas em Diniz et al. (2007) na organização destes dados. Feitos os devidos ajustes, para o ano de 2002-03, restaram 7.245 famílias nas 11 cidades.

No que diz respeito aos rendimentos, Diniz et. al. (2007) comparam as rendas da POF 2002-03 com a da PNAD 2002 e mostram que existem diferenças importantes na formação da renda entre as duas pesquisas. De acordo com a avaliação destes autores, nas PNADs, a coleta dos rendimentos abrange amostras mais expressivas, tendo assim maior precisão na mensuração das rendas mais frequentes, ou melhor, que não sofrem variações expressivas durante o ano, como é o caso das aposentadorias e pensões. Entretanto, na PNAD, a coleta da informação é feita com base no último recebimento mensal e não se conta com controles sobre o valor declarado. Por outro lado, na POF, o período de referência dos dados de rendimentos são os 12 meses anteriores ao preenchimento do questionário e as despesas são parâmetros para a renda declarada. Com isso, observa-se na POF uma melhor apuração dos chamados "outros recebimentos", ou seja, daqueles originários de aluguéis, vendas, doações, auxílios, aplicações de capital, assim como uma captação melhor do total da renda.

A Tabela 1, a seguir, apresenta as informações de gastos e renda para as 11 cidades em estudo nos biênios de 1995-96 e 2002-03. Os gastos globais são divididos entre gastos com bens de consumo e demais gastos. Nesta última categoria de gastos, estão incluídas as despesas com impostos e taxas, com aumento no ativo e com a 
redução do passivo. Com base nos microdados da POF, os gastos em consumo foram subdivididos em 12 grupos que são descritos mais adiante.

Tabela 1 - Renda Familiar Per Capita, Gasto Familiar Per Capita e Consumo Familiar Per Capita - Regiões Metropolitanas do Brasil (Valores em R\$ de 2003)

\begin{tabular}{lcccccc}
\hline RM & $\begin{array}{c}\text { Renda fam. per } \\
\text { capita PNAD }\end{array}$ & $\begin{array}{c}\text { Renda fam. per } \\
\text { capita POF (A) }\end{array}$ & $\begin{array}{c}\text { Gasto fam. per } \\
\text { capita global (B) }\end{array}$ & $\begin{array}{c}\text { B/A } \\
(\%)\end{array}$ & $\begin{array}{c}\text { Consumo fam. } \\
\text { per capita (C) }\end{array}$ & $\begin{array}{c}\text { C/B } \\
(\%)\end{array}$ \\
\hline Belém & & & 1996 & & & \\
Fortaleza & 418,65 & 454,01 & 400,79 & 88,3 & 318,38 & 79,4 \\
Recife & 318,44 & 386,42 & 333,07 & 86,2 & 252,88 & 75,9 \\
Salvador & 345,41 & 386,73 & 361,12 & 93,4 & 288,88 & 80,0 \\
B. Horizonte & 410,28 & 427,27 & 390,58 & 91,4 & 313,06 & 80,2 \\
R. de Janeiro & 468,32 & 667,03 & 637,85 & 95,6 & 436,86 & 68,5 \\
São Paulo & 610,65 & 694,11 & 537,64 & 77,5 & 391,12 & 72,7 \\
Curitiba & 680,46 & 830,41 & 716,34 & 86,3 & 499,73 & 69,8 \\
P. Alegre & 624,95 & 770,65 & 704,69 & 91,4 & 486,96 & 69,1 \\
Goiânia & 616,11 & 819,34 & 686,28 & 83,8 & 472,74 & 68,9 \\
D. Federal & - & 692,71 & 555,35 & 80,2 & 375,30 & 67,6 \\
Total & 681,98 & 899,97 & 741,64 & 82,4 & 511,10 & 68,9 \\
\hline & 580,65 & 702,35 & 598,92 & 85,0 & 426,05 & 71,1 \\
Belém & & & 2003 & & & \\
Fortaleza & 276,93 & 320,74 & 334,37 & 104,2 & 262,32 & 78,5 \\
Recife & 269,51 & 387,92 & 395,51 & 102,0 & 283,70 & 71,7 \\
Salvador & 278,42 & 374,00 & 395,44 & 105,7 & 299,60 & 75,8 \\
B. Horizonte & 318,31 & 468,76 & 477,13 & 101,8 & 346,55 & 72,6 \\
R. de Janeiro & 427,05 & 638,07 & 557,66 & 87,4 & 384,16 & 68,9 \\
São Paulo & 529,72 & 695,03 & 665,24 & 95,7 & 487,10 & 73,2 \\
Curitiba & 528,17 & 711,31 & 665,83 & 93,6 & 468,45 & 70,4 \\
P. Alegre & 476,20 & 701,77 & 667,02 & 95,0 & 476,74 & 71,5 \\
Goiânia & 539,45 & 672,24 & 606,92 & 90,3 & 426,33 & 70,2 \\
D. Federal & - & 576,58 & 539,16 & 93,5 & 400,98 & 74,4 \\
Total & 681,18 & 832,06 & 791,78 & 95,2 & 540,70 & 68,3 \\
\hline Fonte: cán & 472,70 & 634,46 & 601,07 & 95,0 & 429,44 & 71,4 \\
\hline
\end{tabular}

Fonte: cálculo dos autores a partir dos microdados da PNAD e da POF. Valores de 1996 inflacionados utilizando-se o INPC-IBGE.

Os valores das duas primeiras colunas da Tabela 1 sugerem que, de forma geral, os valores de renda da PNAD encontram-se subestimados, uma vez que as rendas medidas por esta pesquisa são quase sempre menores que aquelas aferidas pela POF. 
Muito provavelmente, como adiantado anteriormente, tal subestimação decorre da mensuração incompleta das fontes de renda não regulares. Entretanto, as duas colunas apontam para um movimento comum de queda da renda entre 1995-96 e 2002-03 (18,6\% no caso da renda da PNAD e 9,7\% para a renda da POF).

A renda e os gastos familiares per capita médios do Brasil Metropolitano apresentam movimentos opostos, quando medidos pelas duas POFs. Em 1996, a renda familiar per capita era de $R \$ 702,35$, caindo para $R \$ 634,46$, em 2003; enquanto

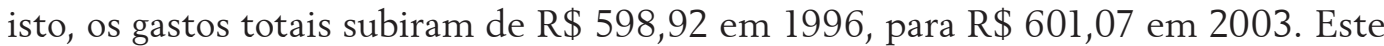
movimento elevou a participação dos gastos como proporção da renda. Mais especificamente, em 1996, os gastos globais no Brasil Metropolitano correspondiam, em média, a $85 \%$ da renda familiar per capita, já, em 2003, esta porcentagem elevou-se para 95\%. Note-se também que, para as cidades do Norte e Nordeste, o gasto familiar per capita médio é superior à renda familiar per capita média no último biênio, o que sugere fontes de renda ainda não declaradas ou apreendidas pela POF nestas regiões. Os gastos em consumo também apresentam elevação entre as duas POFs, mas se mantêm como uma proporção constante dos gastos globais (71\%).

\subsection{A Evolução dos Níveis de Desigualdade entre 1996 e 2003}

Evidências sobre a evolução dos níveis de desigualdade para as distribuições da renda familiar per capita, da despesa familiar per capita global e do consumo familiar per capita entre 1996 e 2003 são obtidas a partir de dois expedientes. Primeiro, considerando-se cada distribuição, são calculados os valores do coeficiente de Gini e de três medidas de Entropia Generalizada, $\operatorname{GE}(\alpha), \alpha=0,1,2$, verificando-se, em seguida, a significância estatística das diferenças entre os valores obtidos para os dois anos. ${ }^{1}$ Numa segunda etapa, é feita uma análise de Dominância de Lorenz para as dinâmicas de evolução das distribuições dos agregados considerados.

Formalmente, o índice de Gini (G) pode ser calculado a partir da relação $G=\sum_{i=1}^{n} \sum_{j=1}^{n}\left|y_{i}-y_{j}\right| /\left(2 \cdot n^{2} \mu\right)$ e as medidas de Entropia Generalizada utilizadas podem ser obtidas como $G E(\alpha)=\left(\frac{1}{\alpha^{2}-\alpha}\right)\left[\frac{1}{n} \sum_{i=1}^{n}\left(\frac{y_{i}}{\mu}\right)^{\alpha}-1\right], \alpha=0,1,2$, onde $y_{i}$ corresponde

1 As escolhas dos valores do parâmetro $\alpha$ igual a 0,1 e 2 decorrem dos diferentes pesos que tais valores atribuem às parcelas das distribuição no cálculo do índice; especificamente, $\alpha=0$ pondera proporcionalmente mais diferenças das observações nas faixas inferiores da distribuição, $\alpha=1$ impõe igual peso ao longo da distribuição e $\alpha=2$ assume maior peso no cálculo do indicador às diferenças das observações na cauda superior da distribuição. Note-se, no mesmo sentido, que $G(0)$ e $G(1)$ correspondem aos tradicionais indicadores de Theil, respectivamente, $L$ e $T$. Veja-se, a respeito, por exemplo, Cowell (1995). 
à renda, ao gasto ou ao consumo familiar per capita da observação $i, \mu$ representa a média da correspondente distribuição e $n$ representa o número de observações considerado. Enfatize-se que tais índices, comumente utilizados em análises sobre dinâmicas de desigualdade, obedecem ao axioma das transferências de DaltonPigou, o que faz a análise da Dominância de Lorenz, levada a efeito em seguida, um complemento importante das evidências geradas (DEATON, 1997).

As Tabelas 2 e 3, a seguir, apresentam inicialmente os valores dos indicadores acima nos anos de 1996 e 2003 e suas respectivas diferenças, respectivamente, para as distribuições da renda familiar per capita, utilizando-se tanto informações da PNAD, como da POF, e para as distribuições do gasto familiar per capita global e do consumo familiar per capita.

Tabela 2 - Níveis de Desigualdade para a Renda Familiar Per Capita - Brasil Metropolitano

\begin{tabular}{|c|c|c|c|c|c|c|}
\hline & \multicolumn{3}{|c|}{ PNAD } & \multicolumn{3}{|c|}{ POF } \\
\hline & 1996 & 2003 & Diferença & 1996 & 2003 & Diferença \\
\hline Gini & $\begin{array}{l}0,5770 \\
(0,002)\end{array}$ & $\begin{array}{l}0,5802 \\
(0,002)\end{array}$ & $\begin{array}{l}0,0032 \\
(0,002)\end{array}$ & $\begin{array}{l}0,5964 \\
(0,006)\end{array}$ & $\begin{array}{l}0,5990 \\
(0,007)\end{array}$ & $\begin{array}{c}0,003 \\
(0,009)\end{array}$ \\
\hline $\mathrm{GE}(0)$ & $\begin{array}{l}0,5979 \\
(0,004)\end{array}$ & $\begin{array}{l}0,6073 \\
(0,004)\end{array}$ & $\begin{array}{l}0,0093 \\
(0,006)\end{array}$ & $\begin{array}{l}0,6720 \\
(0,015)\end{array}$ & $\begin{array}{l}0,6990 \\
(0,019)\end{array}$ & $\begin{array}{c}0,027 \\
(0,024)\end{array}$ \\
\hline $\mathrm{GE}(1)$ & $\begin{array}{l}0,6398 \\
(0,008)\end{array}$ & $\begin{array}{l}0,6454 \\
(0,006)\end{array}$ & $\begin{array}{l}0,0056 \\
(0,010)\end{array}$ & $\begin{array}{l}0,7143 \\
(0,021)\end{array}$ & $\begin{array}{l}0,7145 \\
(0,026)\end{array}$ & $\begin{array}{l}0,0002 \\
(0,034)\end{array}$ \\
\hline $\mathrm{GE}(2)$ & $\begin{array}{l}1,4060 \\
(0,060)\end{array}$ & $\begin{array}{l}1,3829 \\
(0,049)\end{array}$ & $\begin{array}{c}-0,0231^{*} \\
(0,078)\end{array}$ & $\begin{array}{l}1,6393 \\
(0,127)\end{array}$ & $\begin{array}{l}1,5399 \\
(0,126)\end{array}$ & $\begin{array}{c}-0,0993^{\star} \\
(0,178)\end{array}$ \\
\hline
\end{tabular}

Fonte: cálculo dos autores a partir dos microdados da PNAD e da POF. Valores de 1996 inflacionados utilizando-se o INPC-IBGE.

Obs: desvio padrão entre parênteses obtido a partir da variância derivada por Duclos, Estebam e Ray (2004), para o índice de Gini, e pelo processo sugerido por Duclos e Araar (2006), para as medidas de Entropia Generalizada. ${ }^{2}$ * indica significância estatística a 5\%.

2 As estimativas de desvio padrão para as medidas de desigualdade baseadas nas referências citadas, utilizadas nesta e nas tabelas seguintes, podem ser obtidas a partir do software DASP (Distributive Analysis Stata Package) de Araar e Duclos (2007), sendo validadas por estimativas de bootstrap. 
Tabela 3 - Níveis de Desigualdade para o Gasto Familiar Per Capita Global e para o Consumo Familiar Per Capita - Brasil Metropolitano

\begin{tabular}{|c|c|c|c|c|c|c|}
\hline & \multicolumn{3}{|c|}{ Gasto familiar per capita global } & \multicolumn{3}{|c|}{ Consumo familiar per capita } \\
\hline & 1996 & 2003 & Diferença & 1996 & 2003 & Diferença \\
\hline Gini & $\begin{array}{l}0,5791 \\
(0,005)\end{array}$ & $\begin{array}{l}0,5649 \\
(0,006)\end{array}$ & $\begin{array}{c}-0,0143^{*} \\
(0,008)\end{array}$ & $\begin{array}{l}0,5274 \\
(0,005)\end{array}$ & $\begin{array}{l}0,5148 \\
(0,006)\end{array}$ & $\begin{array}{l}-0,012^{*} \\
(0,07)\end{array}$ \\
\hline $\mathrm{GE}(0)$ & $\begin{array}{l}0,6340 \\
(0,013)\end{array}$ & $\begin{array}{l}0,5950 \\
(0,014)\end{array}$ & $\begin{array}{c}-0,0387^{\star} \\
(0,019)\end{array}$ & $\begin{array}{l}0,5166 \\
(0,010)\end{array}$ & $\begin{array}{l}0,4822 \\
(0,011)\end{array}$ & $\begin{array}{l}-0,034^{*} \\
(0,039)\end{array}$ \\
\hline $\mathrm{GE}(1)$ & $\begin{array}{l}0,6580 \\
(0,018)\end{array}$ & $\begin{array}{l}0,6074 \\
(0,017)\end{array}$ & $\begin{array}{c}-0,0507^{*} \\
(0,025)\end{array}$ & $\begin{array}{l}0,5109 \\
(0,012)\end{array}$ & $\begin{array}{l}0,4828 \\
(0,013)\end{array}$ & $\begin{array}{c}-0,0280^{*} \\
(0,018)\end{array}$ \\
\hline GE(2) & $\begin{array}{l}1,4261 \\
(0,128)\end{array}$ & $\begin{array}{l}1,1377 \\
(0,072)\end{array}$ & $\begin{array}{c}-0,2885^{\star} \\
(0,147)\end{array}$ & $\begin{array}{l}0,8419 \\
(0,034)\end{array}$ & $\begin{array}{l}0,7765 \\
(0,043)\end{array}$ & $\begin{array}{c}-0,0654^{*} \\
(0,055)\end{array}$ \\
\hline
\end{tabular}

Fonte: cálculo dos autores a partir dos microdados da PNAD e da POF. Valores de 1996 inflacionados utilizando-se o INPC-IBGE.

Obs: desvio padrão entre parênteses obtido a partir da variância derivada por Duclos, Estebam e Ray (2004), para o índice de Gini, e pelo processo sugerido por Duclos e Araar (2006), para as medidas de Entropia Generalizada. * indica significância estatística a 5\%.

A observação dos valores das medidas de desigualdade, na Tabela 2, para os dois anos, permite perceber que, mensurados pelos indicadores utilizados, os níveis de desigualdade da renda familiar per capita não apresentam redução entre $1996 \mathrm{e}$ 2003, sejam medidos a partir das informações da PNAD, sejam medidos a partir dos dados da POF. Na verdade, os valores dos índices de Gini e das duas medidas iniciais de Entropia Generalizada (GE(0), GE(1)) apresentam-se, em 2003, maiores que em 1996, para ambas as fontes de informações, embora as diferenças só sejam estatisticamente significantes para a medida GE(2), que indica, na verdade, redução da desigualdade.

Por outro lado, a partir dos valores da Tabela 3, é possível observar que os indicadores de desigualdade, em 2003, para a despesa familiar per capita global e para o consumo familiar per capita, apresentam-se menores que aqueles verificados em 1996; sendo, em todos os casos, as respectivas diferenças estatisticamente significantes a $5 \%$.

Assim, tal conjunto de evidências iniciais indica que, medidos pelo índice de Gini e pelas medidas de Entropia Generalizadas consideradas, os níveis de desigualdade para as distribuições da despesa familiar per capita e do consumo familiar per capita apresentam-se, em 2003, menores que em 1996 para o Brasil metropolitano. Tomando-se os níveis destes gastos como indicadores de bem-estar, tais resultados sugerem melhor distribuição de bem-estar entre a população brasileira metropolitana no ano mais recente; a despeito, enfatize-se o fato de as evidências, de forma geral, não apontarem para uma melhora na distribuição da renda familiar per capita. 
Embora todas as evidências acima apontem para a diminuição da desigualdade na distribuição da despesa e do consumo familiar per capita entre 1996 e 2003, nada garante que as tendências obtidas não sejam vinculadas às características particulares destes índices. Ao menos para o conjunto de indicadores que obedecem ao axioma das transferências de Dalton-Pigou, a análise de Dominância de Lorenz permite obter resultados mais decisivos a respeito do comportamento dos níveis de desigualdade das distribuições, uma vez que tais resultados, quando indicando diminuição ou elevação de desigualdade, se aplicam a todos os indicadores deste conjunto.

Neste sentido, o primeiro passo é a obtenção das Curvas de Lorenz para as distribuições nos dois referidos anos. No caso em análise, tal curva mostra a relação entre a proporção acumulada da população e a proporção acumulada da renda (despesa ou consumo) familiar per capita, quando a população é ordenada de forma crescente com respeito a esta última variável. Diz-se, então, que há Dominância de Lorenz de uma distribuição sobre outra quando, para todos os pontos correspondentes à proporção acumulada da população, a Curva de Lorenz da primeira distribuição encontra-se mais próxima da reta da perfeita igualdade que a Curva de Lorenz obtida para a segunda distribuição, ou seja, quando a diferença entre os valores das Curvas de Lorenz é positiva para todos os pontos correspondentes à proporção acumulada da população. Neste caso, pode-se afirmar que a primeira distribuição apresenta uma renda (despesa ou consumo) menos concentrada que a segunda.

As Figuras 1 e 2 apresentam as diferenças entre os valores das Curvas de Lorenz para os anos de 2003 e 1996, respectivamente, para as distribuições da renda familiar per capita obtidas com informações da PNAD e da POF e os correspondentes limites inferiores e superiores dos intervalos de confiança, obtidos de acordo com a metodologia proposta por Davidson e Duclos (2000). ${ }^{3}$

3 Dada a proximidade dos valores nas Curvas de Lorenz para os dois anos, dificultando a visualização gráfica de diferenças entre as mesmas, optou-se por apresentar as diferenças entre seus valores para os porcentuais acumulados da população. Os resultados apresentados foram obtidos a partir do software DASP (Distributive Analysis Stata Package) de Araar e Duclos (2007). 


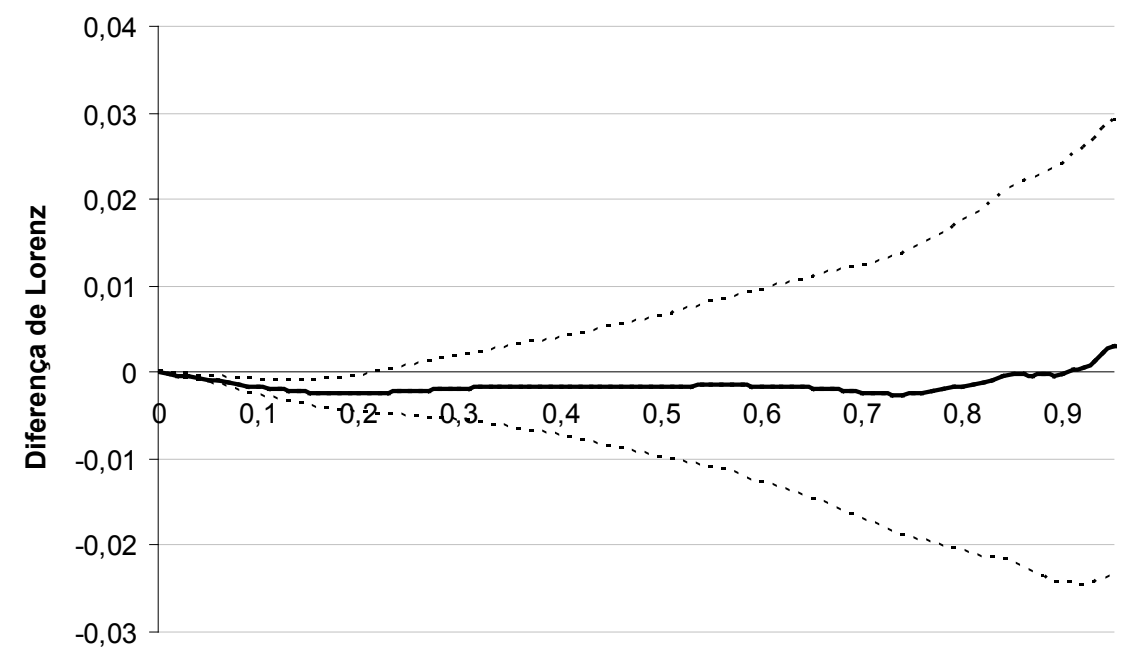

Proporção acumulada da população

Figura 1 - Renda Familiar Per Capita (PNAD): Diferença entre os Valores das Curvas de Lorenz 2003 e 1996 (Eixo Vertical) para Todos os Pontos da Distribuição Acumulada da População (Eixo Horizontal)

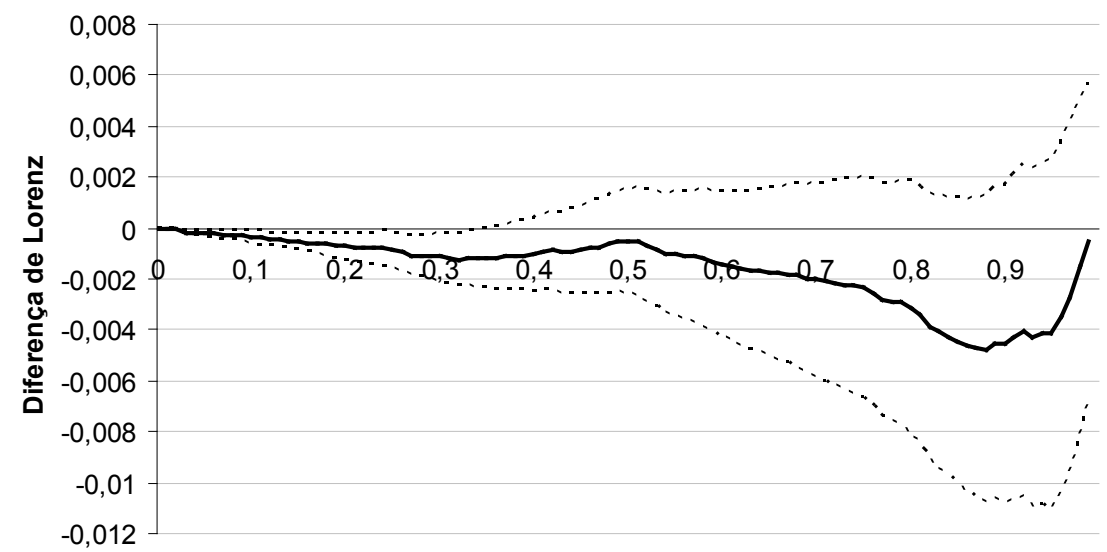

Proporção acumulada da população

Figura 2 - Renda Familiar Per Capita (POF): Diferença entre os Valores das Curvas de Lorenz 2003 e 1996 (Eixo Vertical) para Todos os Pontos da Distribuição Acumulada da População (Eixo Horizontal) 
De acordo com a Figura 1, que considera as diferenças entre os valores da Curva de Lorenz para a distribuição da renda familiar per capita da PNAD para os anos de 2003 e 1996, fica evidente que a grande maioria dos valores são negativos, sugerindo maior concentração de renda em 2003 e em acordo com os valores dos indicadores para os dos anos apresentados na Tabela 1 . Contudo, uma vez que para a maioria dos percentis acumulados da população a diferença de valor zero está incluída no intervalo de confiança, a maioria das diferenças negativas observadas não é estatisticamente significativa ao nível de 5\%. As evidências obtidas para a renda familiar per capita através da POF, apresentadas na Figura 2, indicam comportamento qualitativamente semelhante, ou seja, para a maioria dos percentis acumulados da população, a diferença entre os valores da Curva de Lorenz é negativa, sugerindo maior concentração da renda em 2003, mas não estatisticamente significante ao nível de 5\%.

$\mathrm{Na}$ verdade, estes dois conjuntos de evidências confirmam os resultados da Tabela 2 e indicam que não há Dominância de Lorenz na comparação das distribuições da renda familiar per capita dos anos de 2003 e 1996, quer se usem as informações da PNAD ou se considerem os dados da POF. As Figuras 3 e 4, a seguir, apresentam os resultados da mesma investigação considerando agora, respectivamente, a distribuição do gasto familiar per capita total e a distribuição do consumo familiar per capita.

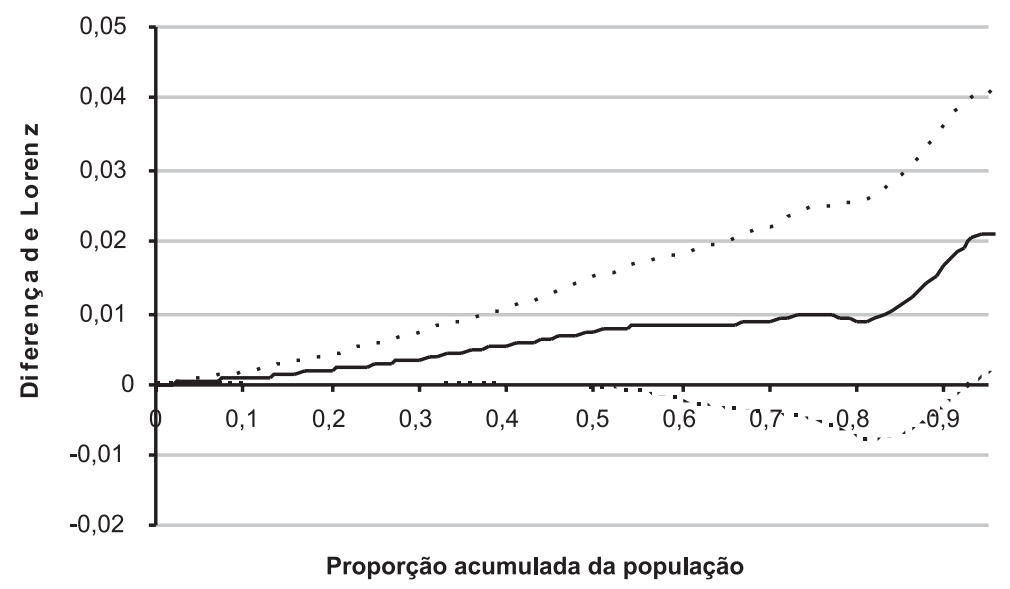

Figura 3 - Despesa Familiar Per Capita Global: Diferença entre os Valores das Curvas de Lorenz 20031996 (Eixo Vertical) para Todos os Pontos da Distribuição Acumulada da População (Eixo Horizontal) 


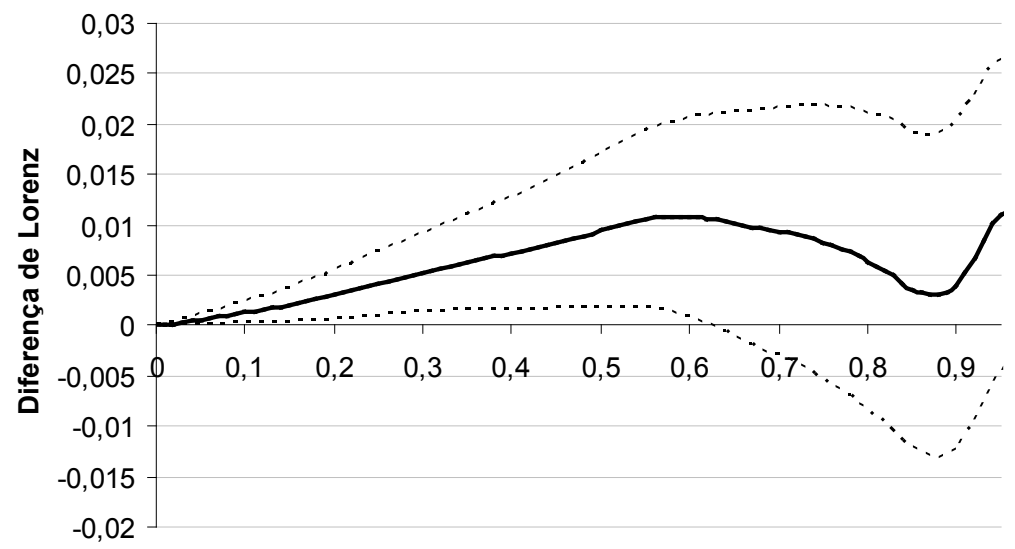

Proporção acumulada da população

Figura 4 - Consumo Familiar Per Capita: Diferença entre os Valores da Curvas de Lorenz 2003 e 1996 (Eixo Vertical) para Todos os Pontos da Distribuição Acumulada da População (Eixo Horizontal)

As evidências obtidas para a distribuição da despesa familiar per capita global, apresentadas na Figura 3, também não indicam a presença de Dominância de Lorenz, uma vez que não se pode rejeitar a hipótese de a diferença entre os valores das Curvas de Lorenz para os dois anos ser igual a zero para todos percentis da distribuição acumulada da população (os intervalos de confiança incluem o valor zero para a maioria destes percentis). Tal evidência indica que o resultado da Tabela 1 quanto à queda da desigualdade mensurada pela diminuição do índice de Gini e dos indicadores de Entropia Generalizada considerados não pode ser generalizado para demais indicadores que obedecem ao axioma das transferências de Dalton-Pigou. Mais especificamente, apenas para os percentis acumulados de 0,93 a 0,99, a hipótese nula de igualdade entre os valores da Curva de Lorenz pode ser rejeitada.

De forma geral, a partir da Figura 4, também não se constata Dominância de Lorenz para a distribuição do consumo familiar per capita dos anos de 2003 e 1996, o que novamente impede a generalização para demais indicadores que obedecem ao axioma das transferências de Dalton-Pigou dos resultados quanto à diminuição da desigualdade da distribuição do consumo familiar per capita verificados na Tabela 1, por meio do índice de Gini e demais indicadores.

Contudo, diferentemente do ocorrido nas análises para as demais distribuições, as evidências apresentadas através da Figura 4 para as distribuições do consumo familiar per capita indicam que os intervalos de confiança para as diferenças entre os valores das Curvas de Lorenz não incluem o valor zero especificamente para os 
percentis acumulados da população no intervalo entre 0,03 e 0,62 (que representa a maior parte da distribuição acumulada da população), ou seja, para tais percentis é possível rejeitar a hipótese nula de que, para cada percentil neste intervalo, a diferença entre os valores das Curvas de Lorenz para os anos de 2003 e 1996 é igual a zero. Percebe-se então que, executando-se uma reduzida parcela da população (correspondente ao intervalo 0,0 e 0,03 da distribuição acumulada da população), as diferenças entre os referidos valores são estatisticamente significantes para as parcelas da população com menor consumo familiar per capita. Tal evidência indica que, em relação à situação em vigor em 1996, tais parcelas menos favorecidas passam a apresentar, em 2003, um maior peso no consumo nas regiões metropolitanas do Brasil. Assim, a diminuição do nível de desigualdade do consumo familiar per capita entre 1996 e 2003, retratada pela diminuição do índice de Gini entre os referidos anos (Tabela 3), reflete este movimento de elevação da participação no consumo das parcelas menos favorecidas.

Desta forma, embora não se possa detectar a presença de Dominância de Lorenz para as dinâmicas das distribuições dos gastos ou consumo familiar entre 1996 e 2003, a elevação do peso do consumo de parte significativa das famílias com menor consumo inicial indica que importantes modificações na distribuição do consumo familiar per capita se efetivaram entre 1996 e 2003. Com o intuito de obter maior entendimento e caracterizar melhor estes movimentos, a partir da decomposição dos níveis de desigualdade dos gastos e do consumo entre os diferentes tipos de despesas para os anos de 1996 e 2003, nas próximas seções são levantadas evidências adicionais sobre as dinâmicas de desigualdade observadas, o que é levado a efeito em duas etapas. Primeiro, investiga-se a importância da dinâmica da desigualdade dos gastos familiares em consumo para a dinâmica da desigualdade dos gastos familiares globais. Em seguida, são fornecidas evidências a respeito da influência dos diferentes gastos em consumo para o comportamento observado para a evolução da desigualdade deste gasto apontada acima.

\section{Decomposição da Evolução da Desigualdade da Renda e dos Gastos entre 1996 e 2003 para o Brasil Metropolitano}

\subsection{Metodologia}

Neste trabalho, os níveis de desigualdade de gastos totais e suas mudanças entre 1996 e 2003 são decompostos a partir da mesma metodologia utilizada recentemente por Hoffmann $(2004,2006)$ e Soares (2006a, 2006b) para a desigualdade de renda no Brasil. Em uma situação em que os gastos totais resultam da agregação 
de diferentes tipos de gastos (ex. consumo e não consumo), o coeficiente de Gini pode ser expresso pela soma das razões ou coeficientes de concentração multiplicados pelos respectivos pesos dos diferentes tipos de gastos. ${ }^{4} \mathrm{Ou}$ seja, formalmente, o valor do coeficiente de Gini (G) pode ser expresso como:

$$
G=\sum_{i=1}^{n} \alpha_{i} C_{i}
$$

onde $n$ é o número de diferentes tipos de gastos da população em foco, $\alpha_{i}$ corresponde à participação da parcela $i$ no gasto total e $C_{i}$ é a razão ou razão de concentração da mesma parcela. Por sua vez, esta última razão ou coeficiente é obtido a partir da curva de concentração, que mostra como, mantida a ordenação crescente do gasto total, a proporção acumulada da parcela $i$ varia em função da proporção acumulada da população. Mais especificamente, definindo $\beta_{i}$ como a área entre a curva de concentração para a fonte $i$ e o eixo das abscissas, a razão ou razão de concentração referente a esta parcela é obtida como:

$$
C_{i}=1-2 . \beta_{i}
$$

onde se pode mostrar que $-1<C_{i}<1$. Tal intervalo, que difere daquele do índice de Gini $(0 \leq G<1)$, decorre do fato de que, já que a ordenação no eixo das ordenadas é dada através da ordenação crescente do gasto total (e não da parcela $i$ desta despesa), a curva de concentração não é convexa como a Curva de Lorenz, e pode estar acima da diagonal da perfeita desigualdade.

Para duas datas, $t$ e $t$-1, é possível observar, pois, quanto da variação do índice de Gini é determinado pela variação da desigualdade das diferentes parcelas ou fontes de gasto (efeito concentração) e quanto deriva da variação das participações destas parcelas ou fontes no gasto total (efeito participação). Como utilizado por Hoffmann (2006), a partir dos índices de Gini nas correspondentes datas, é possível obter:

$$
\Delta G=\sum_{i=1}^{n}\left(\alpha_{i t} C_{i t}-\alpha_{i t-1} C_{i t-1}\right)
$$

4 Decomposições semelhantes podem ser feitas para outros indicadores de desigualdade, como por exemplo, para as medidas de Entropia Generalizada, GE $(\alpha)$. Por razóes de espaço e dada a maior popularidade do índice de Gini, apresenta-se apenas a decomposição para este índice. Para exemplos de aplicações com outros indicadores, veja-se Jenkins (1995), com decomposição das medidas GE $(\alpha)$ aplicada ao Reino Unido, e Hoffman (2006), que considera a decomposição de outros indicadores na análise da evolução da desigualdade brasileira por diferentes fontes de renda. 
resultado que também pode ser expresso como:

$$
\begin{aligned}
& \Delta G=\sum_{i=1}^{n}\left(\bar{C}_{i}-\bar{G}\right) \Delta \alpha_{i}+\sum_{i=1}^{n} \bar{\alpha}_{i} \Delta C_{i}, \text { onde } \bar{G}=\frac{1}{2}\left(G_{t}+G_{t-1}\right) \quad \mathrm{e} \\
& \bar{\alpha}_{i}=\frac{1}{2}\left(\alpha_{i t}+\alpha_{i t-1}\right)
\end{aligned}
$$

Com a primeira soma representando um efeito participação, observa-se que o aumento da participação de uma parcela do gasto que apresenta um nível de concentração menor (maior) que aquele verificado para o gasto total contribui para diminuição (aumento) da desigualdade da renda total. Já a segunda soma, que representa um efeito concentração total, mostra o impacto de variações nos níveis de concentração das diferentes parcelas ou fontes de gasto na variação do nível de desigualdade do gasto total.

\subsection{Decomposição da Desigualdade da Distribuição dos Gastos Globais e do Consumo}

A Tabela 4, a seguir, apresenta uma primeira decomposição possível para os gastos totais, aquela entre os gastos de consumo e demais gastos. Como os gastos de consumo estão mais diretamente vinculados aos níveis de bem-estar da população, é interessante saber, a princípio, em que medida a queda da desigualdade dos gastos totais verificada acima a partir do índice de Gini é explicada pela dinâmica destes gastos, uma situação que poderia ser mais rigorosamente interpretada como de diminuição de desigualdade de bem-estar entre a população.

Duas observações imediatas podem ser feitas a respeito dos números apresentados. Primeiro, os gastos de consumo representam mais de $70 \%$ dos gastos totais e tal parcela apresenta um pequeno aumento entre 1996 e 2003. Segundo, nota-se que os gastos em consumo apresentam um índice de concentração inferior ao dos demais gastos, em ambos os anos. Relembre-se, a este respeito, que os demais gastos são compostos pelos impostos, taxas e aquisição de imóveis e veículos; desta forma, em certa medida, é esperado que este tipo de gastos esteja concentrado na parcela das famílias com maior dispêndio per capita. 
Tabela 4 - Participação dos Diferentes Gastos nos Gastos Globais $\left(\alpha_{I}\right)$ e Razões de Concentração $\left(C_{i}\right)$ para o Índice de Gini dos Gastos Globais Per Capita Brasil Metropolitano

\begin{tabular}{lll|ccc}
\hline & \multicolumn{2}{c|}{$\alpha_{i}$} & & \multicolumn{2}{c}{$C_{i}$} \\
\cline { 2 - 3 } \cline { 5 - 6 } & 1996 & 2003 & & 1996 & 2003 \\
\hline Consumo & 0,711 & 0,714 & & 0,511 & 0,502 \\
Demais Gastos & 0,289 & 0,286 & & 0,747 & 0,720 \\
Gastos Globais & 1,000 & 1,000 & & 0,579 & 0,564 \\
\hline
\end{tabular}

Fonte: cálculo dos autores a partir dos microdados da PNAD e da POF. Valores de 1996 inflacionados utilizando-se o INPC-IBGE.

A partir dos coeficientes de concentração da Tabela 4, observa-se que o grau de concentração dos dois itens que compõem os gastos totais foi reduzido entre $1996 \mathrm{e}$ 2003. Em particular, note-se que o índice de concentração dos gastos em consumo (demais gastos) era de 0,511 (0,747) em 1996, caindo para 0,502 (0,720) em 2003. Tal movimento, em conjunção com o aumento da participação deste tipo de gasto no total dos gastos, sugere que tal parcela dos gastos totais deve ter contribuído através de ambos os efeitos, participação e concentração, para redução da desigualdade dos gastos totais no Brasil metropolitano. De fato, os números da Tabela 5, a seguir, confirmam tal expectativa.

Tabela 5 - Decomposição da Variação do Índice de Gini $(\Delta G)$ para os Gastos Globais - Brasil Metropolitano - 1996-2003

\begin{tabular}{lcccccc}
\hline & $\begin{array}{c}\text { Efeito } \\
\text { Participação } \\
(\mathrm{EP})\end{array}$ & $\begin{array}{c}\text { Efeito } \\
\begin{array}{c}\text { Concentração } \\
(\mathrm{EC})\end{array}\end{array}$ & $\begin{array}{c}\text { Efeito } \\
\text { Total }\end{array}$ & $\begin{array}{c}\text { Contrib. do } \\
\text { EP (\%) }\end{array}$ & $\begin{array}{c}\text { Contrib. do } \\
\text { EC (\%) }\end{array}$ & $\begin{array}{c}\text { Contrib. } \\
\text { Total (\%) }\end{array}$ \\
\hline Consumo & $-0,00020$ & $-0,00626$ & $-0,00646$ & 1,38 & 42,80 & 44,18 \\
Demais Gastos & $-0,00050$ & $-0,00776$ & $-0,00817$ & 3,42 & 52,40 & 55,82 \\
Gastos Globais & $-0,00070$ & $-0,01393$ & $-0,01463$ & 4,80 & 95,20 & 100,00 \\
\hline
\end{tabular}

Fonte: cálculo dos autores a partir dos microdados da POF. Valores de 1996 inflacionados utilizandose o INPC-IBGE.

A primeira linha da Tabela 5 revela que tanto o efeito participação como o efeito concentração dos gastos em consumo atuam em termos de reduzir o índice de Gini dos gastos totais, sendo a magnitude do efeito concentração bem superior à do efeito participação. O pequeno aumento da participação dos gastos em consumo, aliado ao fato de a média da razão de concentração destes gastos ser inferior à média do índice de Gini nos dois períodos, faz com que o efeito participação do consumo 
seja negativo (-0.00020), contribuindo assim para que a variação do Gini dos gastos totais também o seja (-0.01463). Da mesma forma, a redução da razão de concentração dos gastos em consumo faz com que o efeito concentração seja mais uma vez negativo (-0.00626), contribuindo para o resultado anterior.

Nas últimas três colunas da primeira linha, encontram-se o porcentual de quanto a variação dos gastos em consumo contribuiu para a desconcentração dos gastos totais. Percebe-se que os gastos em consumo foram responsáveis por quase a metade da desconcentração dos gastos totais $(44,2 \%)$, dos quais $1,4 \%$ foi devido ao efeito participação e 43,1\% deveu-se ao efeito concentração. Por outro lado, a segunda linha da Tabela 5 revela a participação dos demais gastos sobre a redução da concentração dos gastos totais medida pelo Gini. Note-se que tais gastos contribuíram com 55,8\% da redução do Gini dos gastos globais, com o efeito participação contribuindo com $3,4 \%$ desta redução e os restantes $52,4 \%$ devendo-se ao efeito concentração.

Este resultado revela que, medida a desigualdade através do coeficiente de Gini, os gastos dos brasileiros nas regiões metropolitanas apresentaram significativa desconcentração de renda após a estabilização econômica advinda do Plano Real e que para este movimento contribuíram tanto os gastos de consumo, que se distribuíram mais a favor dos que consumiam menos no início do período, como os demais gastos. Movimentos que, enfatize-se, ocorrem sem tendência de diminuição da concentração da renda, seja esta medida pela POF ou através da PNAD.

A maior contribuição dos demais gastos na redução do Gini sugere algumas hipóteses interpretativas. O aumento dos tributos e tarifas em geral, juntamente com o congelamento da tabela do imposto de renda, elevaram a carga tributária das classes média e média baixa sugerindo uma redução da progressividade dos impostos das famílias e, por conseguinte, podem ter gerado uma desconcentração dos gastos em não consumo. Por seu turno, como também não houve crescimento da renda per capita, muito provavelmente a desconcentração dos gastos de consumo deve ser explicada, em parte, pela expansão do crédito e melhor planejamento dos gastos em um ambiente de baixa inflação.

Uma maior compreensão de como as despesas em consumo contribuíram para a desconcentração dos gastos globais pode ser obtida a partir de uma decomposição particular da desigualdade destas despesas. Neste sentido, a Tabela 6, a seguir, apresenta as participações e os coeficientes de concentração para diferentes grupos de despesas que compóem os gastos em consumo, o que permite observar, para os dois anos, tanto a importância de cada gasto como o seu grau de concentração em relação àquele da despesa de consumo como um todo. 
Tabela 6 - Participação dos Diferentes Gastos no Consumo Total $\left(\alpha_{i}\right)$ e Razão de Concentração $\left(C_{i}\right)$ para o Índice de Gini da Distribuição dos Gastos Familiares Per Capita em Consumo - Brasil Metropolitano

\begin{tabular}{|c|c|c|c|c|}
\hline \multirow[b]{2}{*}{ Subgrupos de despesa } & \multicolumn{2}{|c|}{$\alpha_{i}$} & \multicolumn{2}{|c|}{$C_{i}$} \\
\hline & 1996 & 2003 & 1996 & 2003 \\
\hline Alimentação & 0,234 & 0,229 & 0,411 & 0,426 \\
\hline Habitação & 0,288 & 0,284 & 0,564 & 0,502 \\
\hline Vestuário & 0,066 & 0,060 & 0,478 & 0,450 \\
\hline Transporte & 0,138 & 0,157 & 0,540 & 0,539 \\
\hline Saúde & 0,091 & 0,083 & 0,584 & 0,594 \\
\hline Higiene e Cuidados Pessoais & 0,019 & 0,025 & 0,471 & 0,439 \\
\hline Serviços Pessoais & 0,016 & 0,014 & 0,553 & 0,547 \\
\hline Recreação e Cultura & 0,035 & 0,036 & 0,629 & 0,617 \\
\hline Educação & 0,049 & 0,066 & 0,650 & 0,686 \\
\hline Despesas Diversas & 0,063 & 0,045 & 0,594 & 0,560 \\
\hline Gastos em consumo & 1,000 & 1,000 & 0,527 & 0,513 \\
\hline
\end{tabular}

Fonte: cálculo dos autores a partir dos microdados da POF. Valores de 1996 inflacionados utilizandose o INPC-IBGE.

Observa-se, inicialmente, que os dois grupos de maior participação nos gastos em consumo são Alimentação e Habitação que, conjuntamente, correspondem a cerca de $50 \%$ do consumo total. Mais especificamente, em 1996, os gastos com Alimentação e Habitação correspondiam, respectivamente, a 23\% e 29\% dos gastos em consumo, participações estas que, em 2003, observaram pequenas reduções (passam, respectivamente, a 22\% e 28\%). Por sua vez, entre 1996 e 2003, os grupos que mais elevaram suas participações nos gastos em consumo foram Transporte (de 14\% para 16\%), Higiene Pessoal (de 1,9\% para 2,5\%) e Educação (de 5\% para 6,6\%).

Em termos de dinâmica de concentração, os valores da Tabela 6 indicam uma redução do Gini nos gastos em consumo no período de 1,5\% (Gini passa de 0,521 em 1996, para 0,514 em 2003). Isto significa que o movimento destes gastos beneficiou não só as famílias de menor gasto total per capita (como observado na Tabela 5), mas também as famílias de menor gasto em consumo per capita.

Note-se, porém, de início, que os subgrupos de despesa com Alimentação, Vestuário e Higiene e Cuidados Pessoais apresentam menores níveis de concentração que aquele observado para o gasto total de consumo em 1996, o que parece de acordo com as expectativas, já que tais grupos apresentam produtos de baixo valor adicio- 
nado, sendo, assim, mais acessíveis. Em 2003, os mesmos três grupos (Alimentação, Vestuário e Higiene e Cuidados Pessoais) permaneciam com despesas menos concentradas que os gastos totais de consumo, havendo mesmo elevação da concentração no caso da Alimentação. Tais movimentos destes subgrupos de despesas sugerem, então, que a redução da concentração dos gastos em consumo deve preponderantemente ser explicada pelos subgrupos inicialmente com despesas mais concentradas.

De fato, dos subgrupos de despesas que apresentavam coeficientes de concentração acima daquele observado para o Gini referente às despesas totais de consumo em 1996, especificamente, Recreação e Cultura, Higiene e Cuidados Pessoais, Habitação, Educação, Despesas Diversas e Transporte, apenas os gastos com Educação apresentam trajetória de elevação da concentração. Este movimento dos gastos com Educação, dados seus potenciais impactos futuros sobre a desigualdade, e aquele das despesas com Habitação, dado o seu peso nos gastos totais de consumo (cerca de 30\% do total), merecem ser destacados.

$\mathrm{Na}$ Tabela 7, a seguir, são apresentados os valores e as contribuições porcentuais dos efeitos participação e concentração (equação (4) de cada tipo de gasto em consumo para a diminuição observada no índice de Gini da distribuição do consumo familiar per capita entre 1996 e 2003.

Tabela 7 - Decomposição da Variação do Índice de Gini $(\Delta G)$ para a Distribuição dos Gastos Familiares Per Capita em Consumo - Brasil Metropolitano

\begin{tabular}{lcccccc}
\hline & $\begin{array}{c}\text { Efeito } \\
\text { Participação } \\
(\mathrm{EP})\end{array}$ & $\begin{array}{c}\text { Efeito } \\
\text { Concentração } \\
(\mathrm{EC})\end{array}$ & $\begin{array}{c}\text { Efeito } \\
\text { Total }\end{array}$ & $\begin{array}{c}\text { Contrib. } \\
\text { do EP } \\
(\%)\end{array}$ & $\begin{array}{c}\text { Contrib. } \\
\text { do EC } \\
(\%)\end{array}$ & $\begin{array}{c}\text { Contrib. } \\
\text { Total } \\
(\%)\end{array}$ \\
\hline Alimentação & 0,00050 & 0,00356 & 0,00406 & $-3,47$ & $-24,52$ & $-27,98$ \\
Habitação & $-0,00006$ & $-0,01780$ & $-0,01785$ & 0,39 & 122,64 & 123,03 \\
Vestuário & 0,00031 & $-0,00179$ & $-0,00148$ & $-2,16$ & 12,33 & 10,17 \\
Transporte & 0,00037 & $-0,00016$ & 0,00021 & $-2,55$ & 1,13 & $-1,42$ \\
Saúde & $-0,00056$ & 0,00091 & 0,00035 & 3,84 & $-6,27$ & $-2,42$ \\
Higiene e Cuidados Pessoais & $-0,00038$ & $-0,00070$ & $-0,00108$ & 2,63 & 4,81 & 7,44 \\
Serviços Pessoais & $-0,00006$ & $-0,00010$ & $-0,00016$ & 0,42 & 0,67 & 1,09 \\
Recreação e Cultura & 0,00010 & $-0,00043$ & $-0,00034$ & $-0,68$ & 3,00 & 2,32 \\
Educação & 0,00254 & 0,00207 & 0,00461 & $-17,52$ & $-14,27$ & $-31,79$ \\
Despesas Diversas & $-0,00103$ & $-0,00181$ & $-0,00284$ & 7,08 & 12,48 & 19,56 \\
\hline Gastos em Consumo & $\mathbf{0 , 0 0 1 7 4}$ & $-0,01625$ & $-0,01451$ & $-12,02$ & 112,02 & 100,00 \\
\hline
\end{tabular}

Fonte: cálculo dos autores a partir dos microdados da POF. Valores de 1996 inflacionados utilizandose o INPC-IBGE. 
Como já sugerido pelas evidências da Tabela 6, os valores apresentados na Tabela 7 indicam que o grupo de produtos que mais contribuiu para a redução da concentração foi o dos gastos com Habitação. Uma vez que a razão de concentração média do grupo Habitação entre os dois anos é superior à média do índice de Gini no período, a queda da participação deste grupo no consumo total influencia positivamente na redução de 0,39\% do Gini. Da mesma forma, uma vez que os gastos com o grupo Habitação têm uma alta participação nos gastos totais, a queda na sua razão de concentração influencia positivamente na redução do Gini (122,6\%).

O segundo grupo de maior impacto favorável à redução do Gini é o gasto com Despesas Diversas. Como a sua razão de concentração média nos dois períodos é superior à média do índice de Gini, a expressiva queda na participação deste grupo nas despesas em consumo reflete-se positivamente na redução do Gini $(-7,08 \%)$. Esta contribuição negativa é reforçada pela queda na razão de concentração, responsável por uma contribuição positiva sobre o efeito total em $12,58 \%$. Desta forma, conjuntamente, os efeitos participação e concentração contribuem em 19,56\%, para redução do Gini da distribuição do Consumo.

A redução do Gini da distribuição do consumo familiar per capita só não ocorre de forma mais acentuada em virtude do aumento na concentração dos gastos de dois importantes grupos de produtos: Educação e Alimentação. Ambos apresentaram efeitos participação e concentração no sentido de elevação do índice de Gini da distribuição do consumo familiar per capita. Em particular, tais efeitos para os gastos em Educação ocorrem devido a elevações das participações destes gastos no total de consumo (representando 6,6\% dos gastos totais em consumo) e de movimentos de maior concentração destes gastos a partir de níveis já inicialmente elevados de concentração (o efeito concentração para os gastos em Educação é de mais de 14\% da variação do Gini).

Estes movimentos em sentidos contrários de acordo com os diferentes tipos de gastos em consumo (pró e contra a redução do Gini para distribuição dos gastos familiares per capita em consumo) permitem levantar algumas hipóteses a respeito da dinâmica do consumo familiar per capita do Brasil metropolitano. Uma primeira hipótese está relacionada com a desconcentração dos gastos em Habitação. Como em tal rubrica estão incluídas as despesas com telefonia e eletricidade, é possível que o movimento em direção à menor desigualdade dos gastos destes componentes esteja associado às privatizações ocorridas no período anterior a 2002, que permitiram o acesso à utilização desses serviços para famílias de menores gastos totais em consumo. Quanto ao movimento dos gastos com Higiene e Cuidados Pessoais, este pode ter ocorrido, ao menos em parte, devido ao barateamento de produtos como 
maquiagem, xampu, perfumes, etc., decorrente da abertura comercial da economia brasileira e, ao mesmo tempo, devido à estabilização de seus preços relativos.

Por outro lado, a expressiva concentração dos gastos no grupo Saúde, juntamente com a redução de sua participação, parece passível de ser entendida a partir de dois movimentos: o barateamento dos remédios, com o surgimento dos genéricos, e a elevação dos gastos com planos de saúde. Segundo Diniz et al. (2007), por exemplo, em 1996, perto de $77 \%$ dos gastos com saúde dos 20\% mais pobres era com remédios. Por sua vez, em 1996, os 20\% mais ricos comprometiam, em média, 33\% de suas rendas com gastos em Saúde, despesas estas que se elevaram para 43\% em 2003.

No que se refere aos gastos com Educação, atente-se que, para as classes de renda mais baixa, tal despesa é praticamente nula, o que significa que o aumento da concentração desses gastos ocorre em virtude da elevação dos gastos dos últimos décimos de renda, ou seja, para as famílias de mais elevadas rendas e consumo per capita. Além disto, como revelam Castro e Vaz (2007), os preços relativos dos serviços educacionais praticamente não se alteraram entre 1996 e 2003 quando medidos pelo IPC-FIPE, o que sugere que o aumento da concentração para os gastos em serviços educacionais decorre da maior utilização efetiva destes serviços por parte das classes de média e elevada rendas, provavelmente ou sobretudo o ensino superior.

Por fim, a maior concentração dos gastos com alimentação pode ter tido sua origem, em parte, no barateamento de produtos antes considerados bens de luxo. Produtos como carne de primeira, derivados do leite e frutas, por exemplo, que, em 1996, apresentavam uma alta elasticidade-renda (MENEZES et al., 2007), apresentaram redução de seus preços relativos, o que teria aumentado seu consumo por parte das faixas de renda mais elevadas. Tais produtos, contudo, permanecem inacessíveis para as classes de menor consumo familiar per capita.

\section{Diferenciações Regionais: Decompondo a Dinâmica da Desigualdade do Consumo para as Regiões Metropolitanas do Recife e de São Paulo}

Como mostrou recentemente Hoffman (2006), a diminuição da desigualdade de renda ocorrida no Brasil nos últimos anos apresenta importantes diferenças regionais. Em particular, por exemplo, enquanto, para a região Nordeste, a evolução das transferências públicas de renda apresenta papel preponderante na explicação desta queda da desigualdade, para os Estados da região Sudeste, tal dinâmica desta fonte de renda é muito menos importante, estando a redução da desigualdade mais 
vinculada à dinâmica da renda do trabalho. $\mathrm{Na}$ medida em que as transferências de renda estão direcionadas para famílias de baixa renda, com mais alta propensão a consumir, deve-se esperar diferenciações regionais também quanto à dinâmica de evolução da desigualdade dos gastos familiares e, em particular, dos gastos em consumo.

A partir dos casos específicos das regiões metropolitanas de Recife, a mais populosa da macrorregião mais pobre do País (Nordeste), e São Paulo, a mais populosa da macrorregião mais rica do País (Sudeste), são apresentadas, nesta subseção, evidências a respeito das distinções regionais quanto à dinâmica de desigualdade dos gastos familiares per capita. ${ }^{5}$

Em 1996, não apenas a renda per capita de Recife era mais do que 50\% inferior àquela da RM de São Paulo (Tabela 1), como também o nível de concentração da renda familiar per capita, medido pelo índice de Gini, era também bem maior. De acordo com os valores apresentados na Tabela 8 , apresentada a seguir, neste referido ano, o índice de Gini em Recife era de 0,626, enquanto, em São Paulo, seu valor correspondia a 0,562 . Diferenciações entre as duas RMs, no mesmo sentido, também eram observadas quanto às disparidades nas distribuições dos gastos e do consumo familiar per capita. Especificamente, na RM de São Paulo, os índices de Gini para as distribuições dos gastos globais e do consumo familiar per capita correspondiam a 0,557 e 0,505, respectivamente; por sua vez, na RM do Recife, tal indicador para as distribuições dos gastos globais e do consumo familiar per capita eram de 0,590 e 0,547 , na mesma ordem.

Os resultados da Tabela 8 e as Figuras 5 a 10, que apresentam a análise da Dominância de Lorenz para as distribuições da renda familiar per capita, gasto familiar per capita global e consumo familiar per capita para as duas RMs consideradas, sugerem, além disto, que as dinâmicas de evolução da renda e dos gastos observadas no Brasil, entre 1996 e 2003, apresentam importantes diferenciações regionais.

De acordo com as evidências apresentadas e considerando-se inicialmente a dinâmica da distribuição da renda familiar per capita em 2003, o índice de Gini para a distribuição da renda familiar per capita na RM do Recife reduz-se para 0,578, diminuição esta estatisticamente diferente de zero. Em São Paulo, embora também seja possível observar redução do Gini entre 2003 (0,547) e 1996 (0.562), tal diferença não apresenta significância estatística.

5 Em 2003, cerca de 34,4\% da população nordestina que vivia nas RMs da região localizava-se na RM do Recife; por sua vez, a RM de São Paulo continha 54,1\% da população de todas as RMs do Sudeste. Os resultados para demais RMs do País, não apresentados por razões de espaço, podem ser prontamente disponibilizados pelos autores. 
Tais diferenciações regionais também podem ser observadas a partir das Figuras 5 e 6, que apresentam as Diferenças de Lorenz para as proporções acumuladas da população, respectivamente, para as RMs de Recife e São Paulo. Note-se, primeiro, que não se pode afirmar que haja Dominância de Lorenz em qualquer dos casos das Figuras 5 e 6, ou seja, considerando-se toda a distribuição acumulada da população, em algum ponto da distribuição, nos dois casos, o intervalo de confiança para as diferenças entre as Curvas de Lorenz inclui o valor zero. Porém, também se percebe que, enquanto na Figura 5 (RM do Recife) o zero se mantém fora do intervalo de confiança entre as proporções 0,42 e 0,91, o que indica elevação do peso na renda total da população com renda intermediária, o intervalo de confiança da diferença entre as Curvas de Lorenz para a RM de São Paulo (Figura 6) apresenta o valor zero no seu interior ao longo de toda a distribuição acumulada da população, o que é consistente com a não significância estatística da redução da desigualdade do índice de Gini antes observada.

Resultados no mesmo sentido são observados para a comparação da evolução das desigualdades das distribuições dos gastos e do consumo familiar per capita entre as duas RMs. Na RM de São Paulo, entre 1996 e 2003, os índices de Gini para os gastos globais e para o consumo se reduzem, respectivamente, em 0,02 e 0,01 pontos, diferenças estas não significantemente diferentes de zero (Tabela 8). No mesmo período, na RM do Recife, tal indicador para os gastos globais e para o consumo apresenta redução, respectivamente, de 0,036 e 0,044 pontos, ambas significantes estatisticamente a $10 \%$ e $5 \%$, na mesma ordem (Tabela 8 ).

As análises da Dominância de Lorenz para as distribuições dos gastos e do consumo familiar per capita dos dois anos nas duas regiões metropolitanas são representadas a partir das Figuras 7 a 10. Um exame incial das quatro figuras indica que, novamente, não se pode afirmar que haja Dominância de Lorenz, ou seja, considerandose toda a distribuição acumulada da população, não se pode afirmar que o gasto ou consumo familiar per capita, em 2003, é mais bem distribuído que aquele de 1996, resultado válido para as duas RMs. Todavia, tanto para a distribuição dos gastos como, principalmente, para a do consumo familiar per capita, as Diferenças de Lorenz positivas apresentam-se estatisticamente significantes para intervalos maiores da distribuição acumulada da população na RM do Recife. Mais específica e claramente, o cotejo entre as Figuras 9 e 10 (Diferenças de Lorenz para a distribuição do consumo familiar per capita) permite notar que, enquanto para a RM do Recife a Diferença de Lorenz é positiva e estatisticamente significativa para parcela importante da distribuição acumulada da população (entre 0,42 e 0,95 ), no caso da RM de São Paulo, em nenhuma parcela da distribuição encontra-se significância estatística para a Diferença de Lorenz. 
Tabela 8 - Desigualdade na Distribuição da Renda, Gastos e Consumo Familiar Per Capita Medida pelo Índice de Gini entre 1996-2003 nas RMs de Recife e São Paulo

\begin{tabular}{|c|c|c|c|c|c|c|}
\hline & \multicolumn{2}{|c|}{ Renda familiar per capita } & \multicolumn{2}{|c|}{ Gasto familiar per capita global } & \multicolumn{2}{|c|}{ Consumo familiar per capite } \\
\hline & Recife & São Paulo & Recife & São Paulo & Recife & São Paulo \\
\hline \multirow{3}{*}{1996} & 0,6266 & 0,5623 & 0,5901 & 0,5575 & 0,5545 & 0,5113 \\
\hline & $(0,010)$ & $(0,014)$ & $(0,009)$ & $(0,012)$ & $(0,008)$ & $(0,010)$ \\
\hline & 0,5781 & 0,5475 & 0,554 & 0,5371 & 0,5031 & 0,4946 \\
\hline 2003 & $(0,018)$ & $(0,017)$ & $(0,016)$ & $(0,012)$ & $(0,013)$ & $(0,012)$ \\
\hline Diferença & $\begin{array}{c}-0,0485^{\star *} \\
(0,020)\end{array}$ & $\begin{array}{c}-0,0148 \\
(0,022)\end{array}$ & $\begin{array}{c}-0,0361^{*} \\
(0,018)\end{array}$ & $\begin{array}{l}-0,0204 \\
(0,017)\end{array}$ & $\begin{array}{c}-0,0445^{\star \star} \\
(0,015)\end{array}$ & $\begin{array}{l}-0,010 \\
(0,015)\end{array}$ \\
\hline
\end{tabular}

Fonte: cálculo dos autores a partir dos microdados da POF. Desvio padrão entre parênteses obtido a partir da variância derivada por Duclos, Estebam e Ray (2004).

Obs: ${ }^{* *}$ indica significância estatística a $5 \% \mathrm{e}^{*}$ indica significância a $10 \%$.
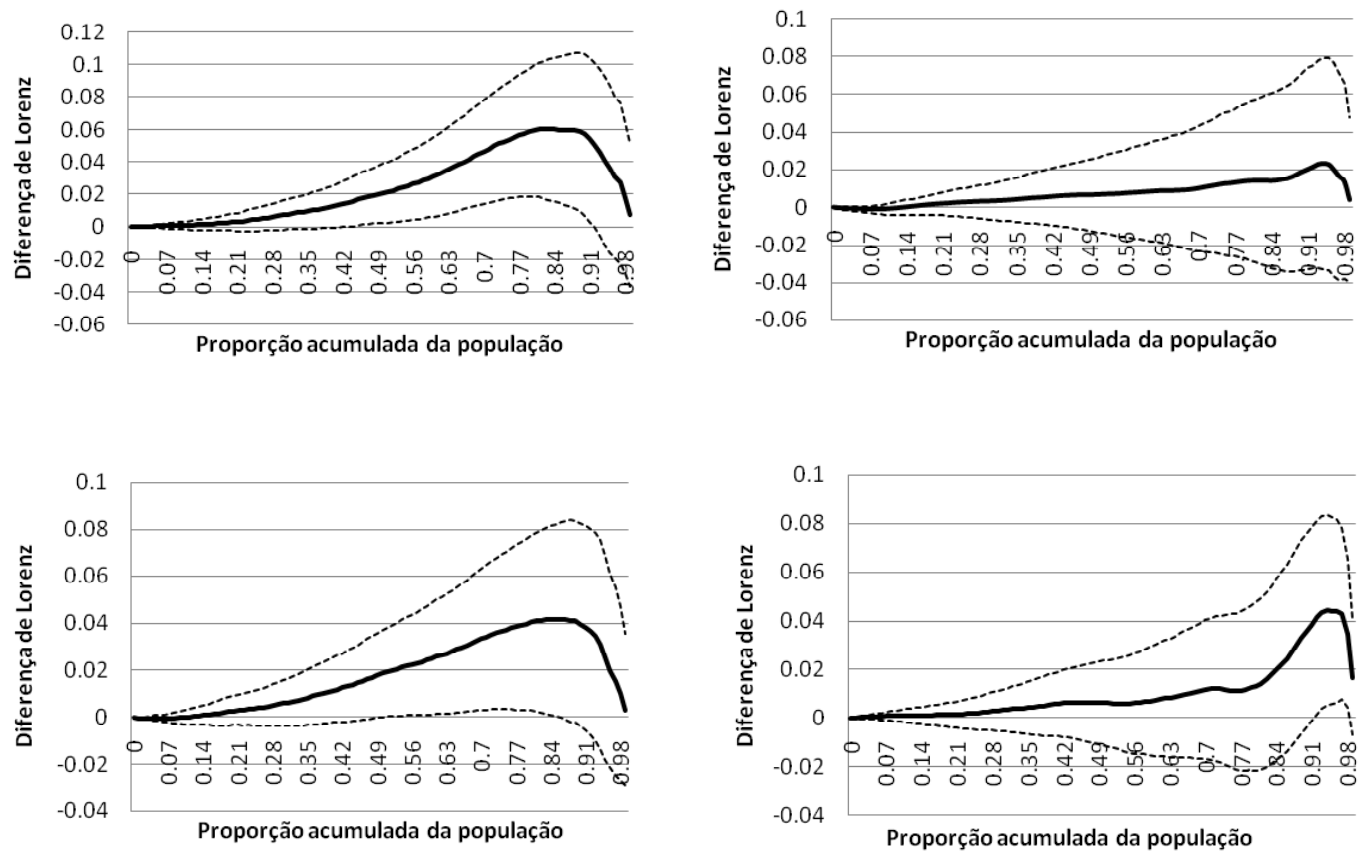

Figura 7 - Gastos Familiares Per Capita

Figura 8 - Gastos Familiares Per Globais na RM do Recife: Capita Globais na RM de Diferença entre os Valores das São Paulo: Diferença entre Curvas de Lorenz 2003 e 1996 os Valores das Curvas de Lorenz 2003 e 1996 


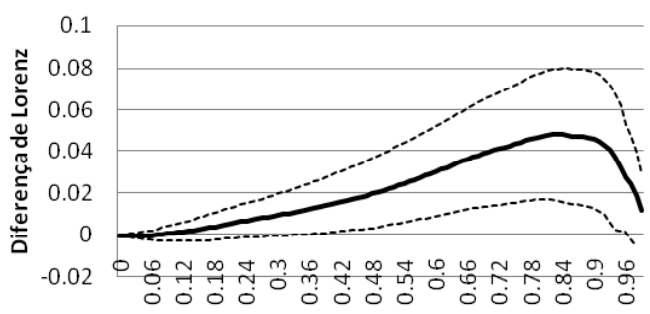

Proporção acumulada da população

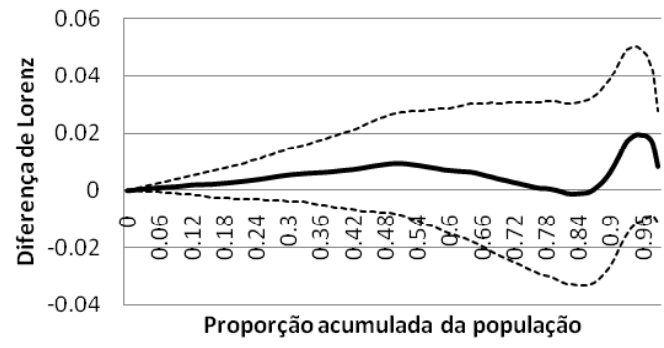

Figura 10 - Consumo Familiar Per Capita na RM de São Paulo: Diferença entre os Valores das Curvas de Lorenz 2003 e 1996

A análise anterior sugere que movimentos mais significativos no sentido de redução na desigualdade observado no Brasil, entre 1996 e 2003, parecem ocorrer nas regiões metropolitanas mais pobres representadas, aqui, pela RM do Recife, onde também estão presentes os mais elevados níveis de concentração de renda e gastos. Tal evidência provavelmente está relacionada com as transferências públicas de renda observadas neste período (HOFFMAN, 2006; SOARES 2006b), já que grande parte destas foi direcionada às regiões Norte e Nordeste, com elevadas concentrações de pobres. É importante salientar que, mesmo após toda a redução acima observada, os índices de Gini, para as distribuições da renda familiar per capita e do gasto familiar per capita na RM do Recife, permanecem superiores àqueles da RM de São Paulo.

\subsection{Diferenciações Regionais na Evolução dos Níveis de Desigualdade dos Dispêndios}

Nesta subseção, na busca de maior entendimento das diferenças regionais quanto às dinâmicas de evolução da desigualdade dos gastos e consumo familiar per capita, procura-se identificar a importância dos diferentes tipos de gastos nos movimentos apontados acima. Seguindo-se expediente análogo àquele da subseção $3.2 \mathrm{e}$ considerando-se as duas RMs de Recife e São Paulo, a partir de decomposições do índice de Gini, em primeiro lugar, são analisadas as influências dos gastos em consumo na dinâmica da desigualdade dos gastos totais; a seguir, são consideradas as influências de componentes específicos do consumo familiar per capita na dinâmica de desigualdade desta despesa. 
A partir da decomposição do índice de Gini para os gastos totais entre consumo e demais despesas, a Tabela 9, a seguir, já apresenta diferenças importantes entre as duas RMs. Primeiro, note-se que, em ambos os casos, há redução da desigualdade do gasto familiar per capita (medida pelo índice de Gini), sendo tal movimento de responsabilidade tanto dos gastos de consumo como dos demais gastos (ambos os coeficientes de concentração diminuem nas duas RMs). Entretanto, esta diminuição da desigualdade é maior e estatisticamente significante na RM do Recife, onde a parcela dos gastos em consumo também é sempre maior do que em São Paulo.

Tabela 9 - Participação dos Gastos nos Gastos Globais $\left(\alpha_{i}\right)$ e Razão de Concentração $\left(C_{i}\right)$ para o Índice de Gini da Distribuição do Gasto Familiar Per Capita Global 1996-2003 - RMs do Recife e de São Paulo

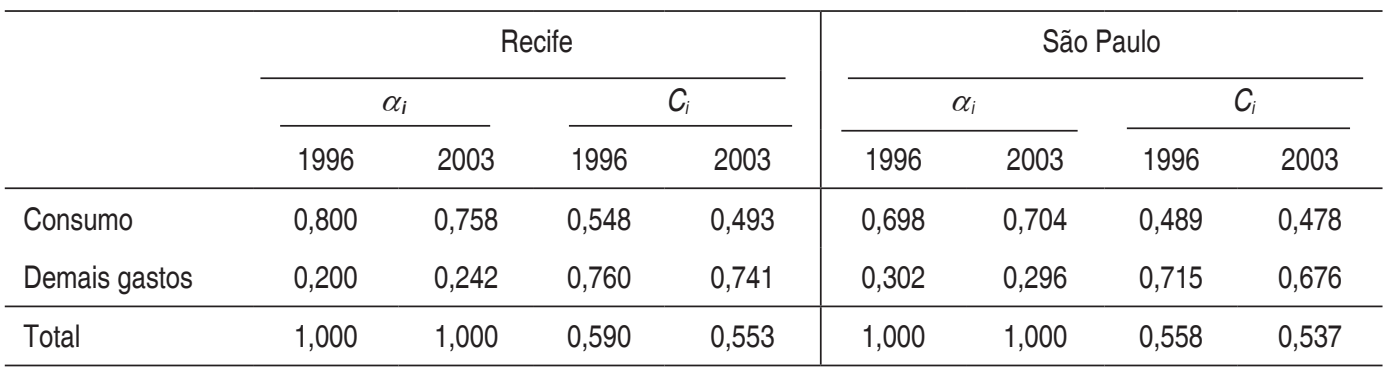

Fonte: cálculo dos autores a partir dos microdados da POF. Valores de 1996 inflacionados utilizandose o INPC-IBGE.

Tais valores são utilizados para obtenção das contribuições dos efeitos participação e concentração para evolução da desigualdade dos gastos nas RMs do Recife e de São Paulo, apresentadas na Tabela 10, a seguir.

Tabela 10 - Decomposição da Variação do Índice de Gini $(\Delta G)$ para a Distribuição do Gasto Familiar Per Capita Global - 1996-2003 - RMs do Recife e de São Paulo

\begin{tabular}{|c|c|c|c|c|c|c|}
\hline & \multicolumn{3}{|c|}{ Recife } & \multicolumn{3}{|c|}{ São Paulo } \\
\hline & $\begin{array}{l}\text { Contrib. do } \\
\operatorname{EP}(\%)\end{array}$ & $\begin{array}{c}\text { Contrib. do } \\
\text { EC (\%) }\end{array}$ & $\begin{array}{l}\text { Contrib. } \\
\text { Total (\%) }\end{array}$ & $\begin{array}{l}\text { Contrib. do } \\
\text { EP (\%) }\end{array}$ & $\begin{array}{l}\text { Contrib. do } \\
\text { EC (\%) }\end{array}$ & $\begin{array}{l}\text { Contrib. } \\
\text { Total (\%) }\end{array}$ \\
\hline Consumo & $-5,87$ & 114,67 & 108,80 & 1,85 & 36,49 & 38,34 \\
\hline Demais Gastos & $-20,47$ & 11,66 & $-8,80$ & 4,33 & 57,33 & 61,66 \\
\hline Gastos Globais & $-26,33$ & 126,33 & 100,00 & 6,18 & 93,82 & 100,00 \\
\hline
\end{tabular}

Fonte: cálculo dos autores a partir dos microdados da POF. Valores de 1996 inflacionados utilizandose o INPC-IBGE. 
Há duas diferenças fundamentais a destacar a respeito dos valores da Tabela 10 . Primeiro, enquanto para o caso da RM do Recife apenas os gastos em consumo contribuem para diminuição da desigualdade, na RM de São Paulo, tanto a dinâmica deste tipo de gasto como aquela dos "demais gastos" contribuem para a queda da desigualdade dos gastos totais nesta RM. Além disto, é notável a diferença entre as RMs quanto ao papel dos gastos em consumo. Na RM do Recife, tal tipo de despesa chega a explicar a totalidade da queda da desigualdade dos gastos totais (108,8\%), enquanto contribui muito menos para o movimento do índice de Gini na RM de São Paulo.

Observe-se que tais diferenciações parecem consistentes, primeiro, com o mais importante papel das transferências públicas de renda na dinâmica de desigualdade de renda na RM do Recife e, segundo, com a maior importância dos "demais gastos" na RM de São Paulo, esta seguramente relacionada com o maior grau de formalização de sua economia. As decomposições dos gastos em consumo para as duas RMs, apresentadas a seguir, favorecem tais associações.

\subsection{Diferenciações Regionais na Evolução dos Níveis de Desigualdade no Consumo}

A partir da mesma subdivisão dos gastos em consumo apresentada para o Brasil metropolitano nas Tabelas 6 e 7 da seção 3, a Tabela 11, a seguir, apresenta as participações e os coeficientes de concentração nos anos de 1996 e 2003 para as distribuições do consumo familiar per capita, respectivamente, das RMs do Recife e de São Paulo.

Tabela 11 - Participação dos Diferentes Gastos no Consumo Total ( $\alpha i)$ e Razão de Concentração $(C i)$ para o Índice de Gini da Distribuição do Consumo Familiar Per Capita

\begin{tabular}{|c|c|c|c|c|c|c|c|c|}
\hline & \multicolumn{4}{|c|}{ Recife } & \multicolumn{4}{|c|}{ São Paulo } \\
\hline & \multicolumn{2}{|c|}{$\alpha_{i}$} & \multicolumn{2}{|c|}{$C_{i}$} & \multicolumn{2}{|c|}{$\alpha_{i}$} & \multicolumn{2}{|c|}{$C_{i}$} \\
\hline & 1996 & 2003 & 1996 & 2003 & 1996 & 2003 & 1996 & 2003 \\
\hline Alimentação & 0,284 & 0,280 & 0,427 & 0,411 & 0,221 & 0,212 & 0,423 & 0,435 \\
\hline Habitação & 0,264 & 0,276 & 0,616 & 0,516 & 0,297 & 0,288 & 0,537 & 0,453 \\
\hline Vestuário & 0,072 & 0,073 & 0,491 & 0,447 & 0,062 & 0,058 & 0,492 & 0,442 \\
\hline Transporte & 0,117 & 0,124 & 0,561 & 0,565 & 0,145 & 0,160 & 0,495 & 0,499 \\
\hline Saúde & 0,093 & 0,086 & 0,656 & 0,602 & 0,094 & 0,078 & 0,553 & 0,549 \\
\hline Higiene e Cuidados Pessoais & 0,024 & 0,033 & 0,487 & 0,398 & 0,018 & 0,022 & 0,497 & 0,432 \\
\hline Serviços Pessoais & 0,016 & 0,014 & 0,543 & 0,536 & 0,016 & 0,014 & 0,534 & 0,509 \\
\hline Recreação e Cultura & 0,030 & 0,029 & 0,695 & 0,579 & 0,035 & 0,038 & 0,601 & 0,607 \\
\hline Educação & 0,053 & 0,054 & 0,702 & 0,641 & 0,047 & 0,075 & 0,628 & 0,680 \\
\hline Despesas Diversas & 0,048 & 0,032 & 0,639 & 0,590 & 0,064 & 0,055 & 0,556 & 0,597 \\
\hline Gastos de consumo total & 1,000 & 1,000 & 0,554 & 0,502 & 1,000 & 1,000 & 0,511 & 0,495 \\
\hline
\end{tabular}

Fonte: cálculo dos autores a partir dos microdados da POF. Valores de 1996 inflacionados utilizandose o INPC-IBGE. 
Além da maior redução da desigualdade da distribuição do consumo familiar per capita, medida pela variação do índice de Gini entre 1996 e 2003, já apontada anteriormente, em relação à participação na despesa total de consumo, a diferença a destacar entre as RMs, na Tabela 11, diz respeito ao maior peso da despesa com alimentação na RM do Recife (28\% do total nesta RM e 21\% na RM de São Paulo em 2003), embora, em ambas as RMs, tal despesa perca espaço para as demais. $\mathrm{Na}$ verdade, na RM do Recife, as alterações mais importantes nas participações são as elevações das despesas com Transporte e Higiene e Cuidados Pessoais, e a redução da participação das Despesas Diversas. Já na RM de São Paulo, destacam-se a elevação das despesas com Educação e Higiene e Cuidados Pessoais, e a redução do peso das despesas com Saúde.

No que diz respeito à concentração, as diferenças regionais são ainda mais marcantes. Na RM do Recife, os únicos gastos que apresentaram elevação da concentração foram os de Transporte. Na RM de São Paulo, entretanto, além do Transporte, os gastos com Alimentação, Recreação e Cultura, Educação e Despesas Diversas também apresentaram maior coeficiente de concentração em 2003. Tais semelhanças e diferenças entre as referidas RMs permitem entender a importância dos diferentes tipos de despesa em consumo para a evolução da desigualdade destes gastos nas duas RMs, mostradas na Tabela 12, a seguir:

\section{Tabela 12 - Decomposição da Variação do Índice de Gini $(\Delta G)$ para a Distribuição do Consumo Familiar Per Capita (\%) - Regiões Metropolitanas do Recife e de São Paulo - 1996-2003}

\begin{tabular}{lrrr|rrrr}
\hline & \multicolumn{4}{c}{ Recife } & & \multicolumn{3}{c}{ São Paulo } \\
\cline { 2 - 3 } & $\begin{array}{r}\text { Contrib. } \\
\text { do EP }\end{array}$ & $\begin{array}{c}\text { Contrib. } \\
\text { do EC }\end{array}$ & $\begin{array}{c}\text { Contrib. } \\
\text { Total }\end{array}$ & & $\begin{array}{c}\text { Contrib. } \\
\text { do EP }\end{array}$ & $\begin{array}{c}\text { Contrib. } \\
\text { do EC }\end{array}$ & $\begin{array}{c}\text { Contrib. } \\
\text { Total }\end{array}$ \\
\hline Alimentação & $-0,76$ & 8,63 & 7,87 & & $-4,34$ & $-16,11$ & $-20,45$ \\
Habitação & $-0,88$ & 51,93 & 51,04 & $-0,43$ & 146,15 & 145,73 \\
Vestuário & 0,09 & 6,09 & 6,18 & $-0,93$ & 18,03 & 17,10 \\
Transporte & $-0,41$ & $-0,87$ & $-1,28$ & 0,49 & $-3,68$ & $-3,19$ \\
Saúde & 1,38 & 9,22 & 10,60 & 4,76 & 2,31 & 7,07 \\
Higiene e Cuidados Pessoais & 1,41 & 4,84 & 6,26 & 1,05 & 7,89 & 8,94 \\
Serviços Pessoais & 0,04 & 0,20 & 0,24 & 0,16 & 2,23 & 2,39 \\
Recreação e Cultura & 0,15 & 6,57 & 6,73 & $-1,67$ & $-1,28$ & $-2,95$ \\
Educação & $-0,40$ & 6,30 & 5,90 & $-25,10$ & $-18,69$ & $-43,79$ \\
Despesas Diversas & 2,65 & 3,81 & 6,46 & 3,94 & $-14,80$ & $-10,86$ \\
\hline Gastos em Consumo & 3,28 & 96,72 & 100,00 & $-22,05$ & 122,05 & 100,00 \\
\hline
\end{tabular}

Fonte: cálculo dos autores a partir dos microdados da POF. Valores de 1996 inflacionados utilizando-se o INPC-IBGE. 
Como verificado para o Brasil metropolitano, nas duas RMs, o principal grupo de despesas com movimento favorável à diminuição da desigualdade do consumo entre 1996 e 2003 foi Habitação. Tanto no Brasil como em São Paulo, os gastos com o grupo Vestuário foram o segundo a apresentar maior movimento favorável à desconcentração. Em Recife, embora este grupo tenha contribuído positivamente para redução da desigualdade, sua contribuição foi mais modesta $(6,2 \%)$. É interessante notar que, enquanto no Brasil as despesas com Saúde contribuíram negativamente para redução do Gini $(-2,4 \%)$, nas RMs de Recife e São Paulo, este grupo apresentou dinâmica favorável à redução da concentração em, respectivamente, 10,6\% e 7,1\%.

Destaque-se também o grupo Educação, cuja dinâmica apresentou forte impacto negativo para redução da desigualdade na RM de São Paulo $(-43,79 \%)$, enquanto, na RM do Recife, seu impacto foi positivo (5,9\%). Tais tendências provavelmente foram influenciadas pelas disparidades regionais de escolaridade (demanda) e pelo crescimento das universidades privadas (oferta). Nas RMs mais pobres como Recife, o crescimento da renda pode elevar os gastos com materiais escolares ou mesmo vir a levar os pais a retirarem as crianças das escolas públicas e as colocarem na escola privada. Por outro lado, na RM de São Paulo, a mais elevada escolaridade e o maior contingente de pessoas com ensino médio completo seguramente estão associados à proliferação das universidades e, assim, ao aumento da parcela da renda gasta com Educação.

Diferenças relevantes entre as RMs são encontradas também nas despesas de Alimentação e de Recreação e Cultura (ambas favoráveis à diminuição da desigualdade na RM do Recife, mas não na RM de São Paulo). Tal comportamento da despesa com Alimentação sugere, mais uma vez, a associação com a queda da desigualdade da renda, por sua vez, associada a maior importância das transferências de renda para a RM do Recife.

\section{Conclusões}

Diferentemente da maior parte das evidências disponíveis, neste trabalho, foram utilizados microdados de gastos e consumo, e não apenas de renda, para avaliar a evolução do nível de desigualdade na distribuição de bem-estar entre a população metropolitana do Brasil entre os biênios 1995-06 e 2002-03. Distinguindo-se do verificado para a distribuição da renda familiar per capita, as evidências encontradas indicam que, medida pelo índice de Gini, a queda da desigualdade ocorre tanto para os gastos como para o consumo familiar per capita, embora não seja possível apontar a presença de Dominância de Lorenz para qualquer das três distribuições entre os dois biênios. Desta forma, este primeiro conjunto de resultados indica que, quando 
medida a desigualdade de bem-estar dos brasileiros metropolitanos por meio da distribuição do consumo familiar per capita, ao invés da distribuição da renda entre os biênios 1995-06 e 2002-03, obtêm-se evidências muito mais favoráveis a uma melhoria da distribuição deste bem-estar na referida população.

A partir da decomposição da variação do índice de Gini para a desigualdade da distribuição dos gastos, as evidências obtidas também indicam que a queda da desigualdade da distribuição do consumo familiar per capita é responsável por cerca de 47,5\% da redução do índice de Gini para a distribuição do gasto familiar per capita global, sendo o restante de responsabilidade das demais despesas (outras despesas correntes, aumento de ativos ou diminuição de passivos). Por sua vez, a decomposição do índice de Gini para a desigualdade da distribuição do consumo indicou que, por um lado, as dinâmicas dos gastos com Habitação, Higiene e Cuidados Pessoais, Vestuário e Recreação e Cultura favoreceram a diminuição da desigualdade na distribuição do consumo e que, por outro, as dinâmicas dos gastos com Educação, Saúde e Alimentação impediram uma diminuição maior desta desigualdade, uma vez que apresentaram maiores níveis de concentração no biênio 2002-03.

Como já havia sido apontado para a evolução da distribuição da renda familiar per capita (HOFFMAN, 2006), a consideração da evolução dos níveis de desigualdade dos gastos dos casos específicos das RMs do Recife e de São Paulo permitiu evidenciar diferenças regionais importantes no País. Tanto para o gasto familiar per capita total como para o consumo familiar per capita, observaram-se movimentos mais favoráveis à redução da desigualdade na RM nordestina. Além disto, medida a desigualdade por meio do índice de Gini, diferentemente do caso da RM de São Paulo, o movimento em direção a melhor distribuição do gasto e do consumo, observado para a RM do Recife entre os biênios 1995-06 e 2002-03, ocorre em meio à redução da desigualdade dos gastos familiares em Alimentação. Este último conjunto de evidências é consistente com a maior importância das transferências públicas de renda na composição da renda familiar nas regiões metropolitanas mais pobres do País e ressalta a importância desta política para redução da desigualdade de bem-estar, sobretudo nestas regiões.

\section{Referências}

ARAAR, A.; DUCLOS, J-Y. DASP: Distributive Analysis Stata Package. User Manual. Université Laval, PEP, CIRPÉE, Banco Mundial, 2007. Mimeo.

BARROS, R. et al. Uma análise das principais causas da queda recente na desigualdade de renda brasileira. Econômica, Rio de Janeiro, v. 8, n. 1, p. 117-147, jun. 2006. 
CASTRO, J. A.; VAZ, F. M. Gastos das famílias com educação. In: SILVEIRA, F. et al. (Org.). Gastos e consumo das famílias brasileiras contemporâneas. Brasília: IPEA, 2007, v. 2, p. 77-104.

COWEL, F. Sampling variance and decomposable inequality measures. Journal of Econometrics, 42, p. 27-41, 1989. 1995.

. Measuring inequality. $2^{\text {and }}$ ed. Hemel Hempstead: Harvest Wheatheaf,

DAVIDSON, R.; DUCLOS, J-Y. Statistical inference for stochastic dominance and for measurement of poverty and inequality. Econometrica, v. 68, n. 6, p. 14351464, 2000.

DEATON, A. The analysis of household surveys: a microeconomic approach to development policy. Baltimore: The John Hopkins University Press, 1997.

DINIZ, B. P. C. et al. As pesquisas de orçamentos familiares no Brasil. In: Silveira, F. et al. (Org.). Gastos e consumo das famílias brasileiras contemporâneas. Brasília: IPEA, 2007, v. 2, p. 17- 74.

DUCLOS, J.-Y.; ESTEBAN, J.; RAY, D. Polarization: concepts, measurement, estimation. Econometrica, 72, p. 1737-1772, 2004.

DUCLOS, J.-Y.; ARAAR, A. Poverty and equity measurement, policy, and estimation with DAD. Berlin; Ottawa: Springer; IDRC, 2006.

FERREIRA, F.H.G. et al. Ascensão e queda da desigualdade de renda no Brasil. Econômica, Rio de Janeiro, v. 8, n. 1, p. 147-171, jun. 2006.

HOFFMANN, R. Mensuração da desigualdade e da pobreza no Brasil. In: HENRIQUES, R. (Org.). Desigualdade e pobreza no Brasil. Rio de Janeiro: IPEA, 2000, p. 81-107.

. Decomposition of Mehran and Piesch inequality measures by factor components and their application to the distribution of per capita household income in Brazil. Brazilian Review of Econometrics, Rio de Janeiro, v. 24, n. 1, p. 149171, maio 2004.

. Transferências de renda e a redução da desigualdade no Brasil e cinco regiões entre 1997 e 2004. Econômica, Rio de Janeiro, v. 8, n. 1, p. 55-81, jun. 2006.

JENKINS, S.P. Accounting for inequality trends: decomposition analysis for the UK, 1971-1986. Economica, 62, p. 139-191, 1995.

KAKWANI, N.; NERI, M.; SON, H. H. Pro-poor growth and social programmes in Brazil. In: ENCONTRO NACIONAL DE ECONOMIA. Anais do Encontro Nacional de Economia, Salvador, 2006.

MENEZES, T. et al. Elasticidade renda dos produtos alimentares nas regiões metropolitanas brasileiras: uma aplicação da POF 1995/1996. Estudos Econômicos, v. 37, n. 2, p. 329-352, 2007.

SOARES, S. Distribuição de renda no Brasil de 1976 a 2004 com ênfase no período entre 2001 e 2004. Brasília: IPEA, fev. 2006a. (Textos para Discussão, n. 1166). 
. Análise de bem-estar e decomposição por fatores da queda na desigualdade entre 1995 e 2004. Econômica, Rio de Janeiro, v. 8, n.1, p. 83-115, jun. 2006b. 